\title{
Porosity and interior structure of flocculated activated sludge floc
}

\author{
H.Y. Chung and D.J. Lee* \\ Chemical Engineering Department, National Taiwan University, Taipei 10617, Taiwan \\ Received 6 December 2002; accepted 27 June 2003
}

\begin{abstract}
This work estimated the porosities of activated sludge flocs, cationic polyelectrolyte flocculated, based on free-settling tests, buoyant weight measurements, and confocal laser scanning microscope (CLSM) tests. The extent of advective flow was estimated based on bubbletracking test. The former two measurements suggested a close-to-unity porosity, that is, an extremely void floc interior. Meanwhile, the latter two tests recommended a dense floc interior with a porosity less than $64 \%$. A discrepancy exists between the porosities estimated by various tests. A floc model was proposed based on the understanding that a vast amount of bound water in the floc was regarded as void in buoyant weight measurement, but was impermeable for advective flow. The distribution rather than the mean value of the porosity controls the advective flow. There existed no simple correlation between the porosities measured by different tests.
\end{abstract}

(c) 2003 Elsevier Inc. All rights reserved.

Keywords: Porosity; Free-settling; Buoyant weight; Floc structure; Bubble-tracking; CLSM; Floc model

\section{Introduction}

Floc size and density are two of the factors that most influencing the performance of floc processes. A free-settling test has been widely employed to estimate these two factors [1]. Sludge flocs are recognized as fractal-like objects in which pores of all sizes (less than that of the floc and greater than that of the primary particles) exist [2-5]. Following a proposal by Lee [6], Wu et al. [7] experimentally demonstrated the fractals-in-fractals structures of sludge flocs. Restated, how primary particles constitute a microfloc presents the first architectural level (local structure), and the way the microflocs network into the entire floc forms the second level of floc structure (global structure).

The structure of the floc interior controls the extent of advective flow, and hence the corresponding hydrodynamic drag force during settling [8]. Several authors [9-12] comprehensively reviewed this topic. The ease of the advective flow through the floc affects the flocculation efficiencies of fine particles in suspension [13-15]. Chellam and Wiesner [16] and Veerapanchi and Wiesner [17] revealed that the extent of advective flow through floc depends on the particle packing characteristics. Tsou et al. $[18,19]$ employed the

\footnotetext{
* Corresponding author.

E-mail address: djlee@ccms.ntu.edu.tw (D.J. Lee).
}

bubble-tracking technique to estimate the extent of advective flow through the waste activated sludge floc.

A common practice for estimating floc porosity is to observe a floc of diameter $d_{f}$ falling freely at terminal velocity of $V(\mathrm{~m} / \mathrm{s})$ in a pool of liquid. Based on the force balance between the buoyant and the hydrodynamic drag force the floc density could be estimated as

$\rho_{f}-\rho=\frac{3 \rho \Omega C_{D}}{4 d_{f} g} V^{2}$,

where $\rho_{f}\left(\mathrm{~kg} / \mathrm{m}^{3}\right)$ and $\rho\left(\mathrm{kg} / \mathrm{m}^{3}\right)$ are the floc density and the water density, respectively; $C_{D}(-)$ is the drag coefficient; $\Omega(-)$ is the correction factor to the advective flow; and $g\left(\mathrm{~m} / \mathrm{s}^{2}\right)$, the gravitational acceleration. The density difference, or the effective floc density, relates the floc porosity to the mass balance expression,

$1-\varepsilon=\frac{\rho_{f}-\rho}{\rho_{m}-\rho}$,

where $\rho_{m}$ is the solid density $\left(\mathrm{kg} / \mathrm{m}^{3}\right)$. Taking $d_{f}=634 \mu \mathrm{m}$, $V=1.15 \mathrm{~mm} / \mathrm{s}, \Omega=1$ (no advective flow), $C_{D}=34 / R e$ (a commonly adopted expression proposed by Tambo and Watanabe [20]), and $\rho$ and $\rho_{m}$ as 1000 and $1450 \mathrm{~kg} / \mathrm{m}^{3}$, respectively, $\varepsilon$ is calculated as 0.995 , a very porous floc interior. This value, in most cases, appears unreasonably high since visual observation normally suggests a not-so-loose floc interior [21]. 
We need detailed information on floc porosity to better understand the sludge processes involving flocs. This work conducted free-settling tests on the flocculated floc. Then the buoyant weight of floc was measured by hanging it on an elastic stick and observing the resulting stick deformation under gravity. The floc structure and the content of advective flow were then explored using fluorescent in situ hybridization (FISH) and confocal laser scanning microscopy (CLSM) [22] and a bubble-tracking technique [18,19], respectively. The discrepancy between the porosities measured by different tests was demonstrated and a floc model was proposed to interpret the experimental findings.

\section{Experimental}

\subsection{The sample}

Waste activated sludge was taken from the Min-Sheng Municipal Wastewater Treatment Plant in Taipei, was gravitationally settled to a solid content of $15,000 \mathrm{mg} / \mathrm{l}$, and was the testing sample for the present test. The $\mathrm{pH}$ value of the sludge was approximately 6.2 . The chemical oxygen demand (COD) for the sludge was $24,400 \mathrm{mg} / 1$, obtained from a direct reading spectrometer (DR/2000, HACH, USA). The COD for the filtrate of sludge sample after filtering through a $0.45-\mu \mathrm{m}$ membrane was termed the soluble COD (SCOD); it $\mathrm{read} 510 \mathrm{mg} / \mathrm{l}$ for the original sludge. The elemental compositions of the dried sample were C: $34.3 \%, \mathrm{H}: 5.5 \%$, and N: $5.5 \%$, using elemental analyzer (Perkin-Elmer $2400 \mathrm{CHN}$ ). The dry solid density of the sludge was measured by an Accupyc Pycnometer 1330 (Micromeritics) as $1450 \mathrm{~kg} / \mathrm{m}^{3}$ $\left(\rho_{m}\right)$.

The cationic flocculant, a polyacrylamide indicated as polymer T-3052, was obtained from Kai-Guan Inc., Taiwan. The polymer T-3052 has an average molecular weight of $10 \mathrm{MDa}$ and a charge density of $20 \%$. The polymer solution was gradually poured into the mixing vessel containing fresh sludge samples with $200 \mathrm{rpm}$ of stirring for $5 \mathrm{~min}$ (rapid mix) followed by $50 \mathrm{rpm}$ of another $20 \mathrm{~min}$ (slow mix). Based on filterability tests (data not shown), the "optimal" dose of polyelectrolyte for the present sludge was $160 \mathrm{ppm}$.

\subsection{Floc settling test}

Figure 1 demonstrates the apparatus of the free-settling test. A glass cylinder $(6 \mathrm{~cm}$ in diameter and $50 \mathrm{~cm}$ in height), sectioned on a side with an attaching plane view glass, was used for a floc-settling test. A JVC camera equipped with a close-up lens was used to record the floc motion. A flat plate was installed in the centerline of the settling column. A floc is released carefully from the top of the column. If the floc did not move along the central line, it would be screened out, while only the one just moving along the centerline could pass. The floc diameter is taken as the equivalent diameter of the projection area of the floc. From the position versus

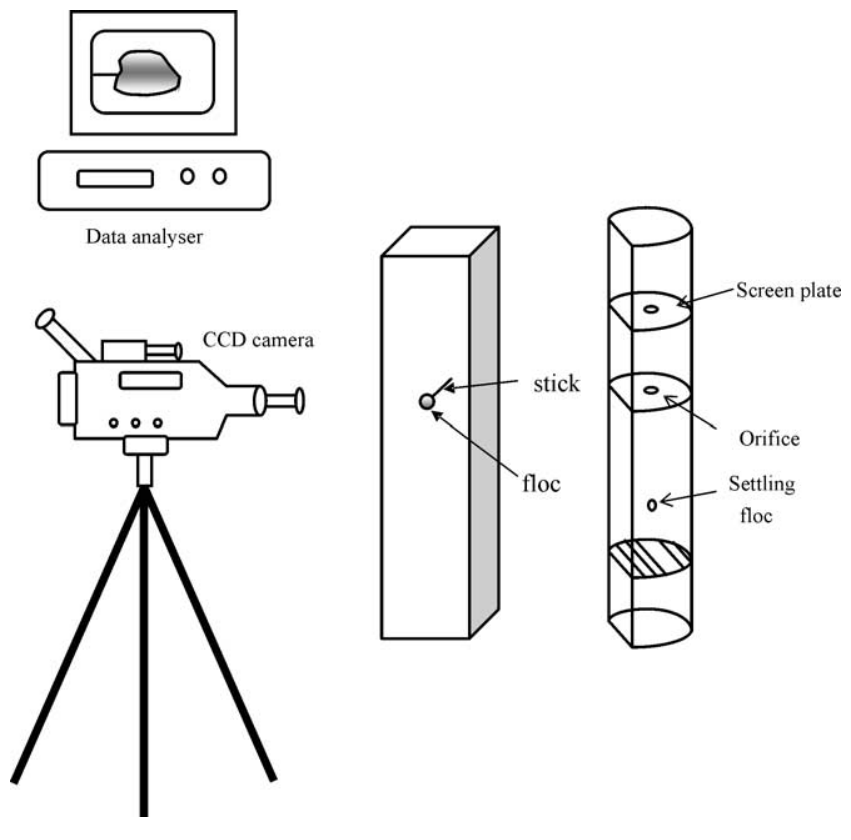

Fig. 1. Experimental setup.

time data the floc terminal speed can be found by numerical differentiation and data smoothing.

\subsection{Floc weight measurement}

The mass of individual flocs is very small, for instance, around $3 \mathrm{mg}$ for a floc of diameter $2000 \mu \mathrm{m}$, giving a buoyant weight of approximately $30 \mu \mathrm{g}$ (see later). A commercial electronic balance cannot measure such a tiny buoyant weight of floc.

We hung the floc on an elastic nylon stick (Sunko, Japan) of diameter $148 \mu \mathrm{m}$ and length $2 \mathrm{~mm}$, respectively. Figure 2a reveals a polystyrene sphere of diameter $1888 \mu \mathrm{m}$ for the sake of comparison. Figure $2 \mathrm{~b}$ demonstrates a microphotograph of flocculated floc at $160 \mathrm{ppm}$ polyelectrolyte, which looks bulky and dense in interior.

Figure 3 schematically demonstrates the stick deformation measurement. The displacement of the stick was measured using a digital camera, JAI 950 1/3" (JAI, 210 pixels in $1 \mathrm{~mm}$ ), equipped with a close-up lens (MML2-110D). Within the linearly elastic regime the stick deformation is proportional to the applied force; that is,

$Y=(1 / E) F_{S}$,

where $Y(\mathrm{~m})$ is the displacement of stick. The polystyrene (PS) sphere demonstrated in Fig. 1 of size $1888 \mu \mathrm{m}$ and density $1060 \mathrm{~kg} / \mathrm{m}^{3}$, giving a buoyant force in water at $25^{\circ} \mathrm{C}$ of $2.17 \times 10^{-6} \mathrm{~N}$, was used to calibrate the applied force. The proportionality constant $E$ was estimated as $1.78 \times 10^{-3} \mathrm{~N} / \mathrm{m}$. With the assistance of Eq. (3) the buoyant weight of the floc could be estimated. A buoyant weight of $30 \mathrm{mg}$ could yield a displacement of $0.2 \mathrm{~mm}$, which could be correctly measured using the present apparatus. 


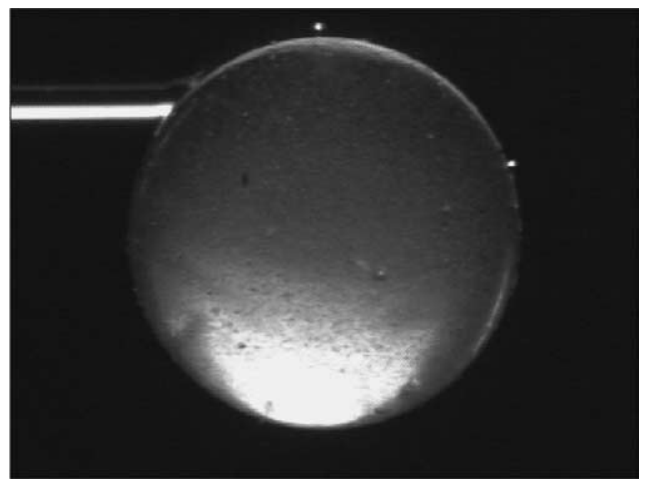

(a)

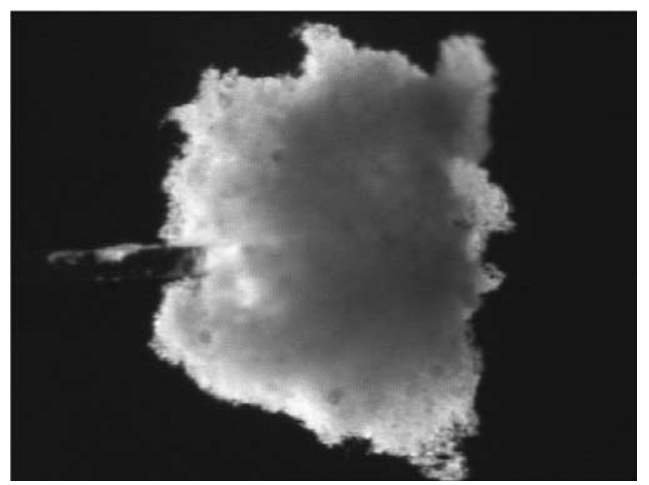

(b)

Fig. 2. Microphotographs of the testing samples. (a) Polystyrene (PS) sphere of diameter $1888 \mu \mathrm{m}$; (b) sludge floc.

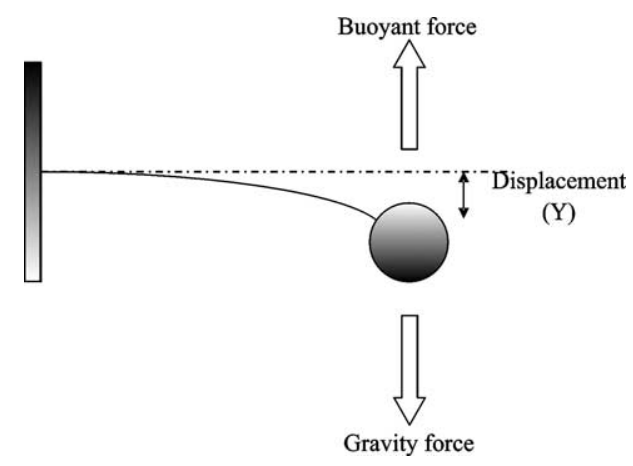

Fig. 3. The schematic for the measurement of the floc density.

\subsection{Bubble-tracking test}

We employed the bubble-tracking technique modified from Tsou et al. [18,19] to estimate the extent of advective flow through the floc. Figure 1 also depicts the schematic of the bubble-tracking testing apparatus. A glass tank $(10 \mathrm{~cm}$ (L) $\times 10 \mathrm{~cm}(\mathrm{~W}) \times 50 \mathrm{~cm}(\mathrm{H}))$ was used for observation. A floc, hung on the above-mentioned elastic stick, was placed normal to the tank wall. Close to the tank bottom a platinum wire of diameter $35 \mu \mathrm{m}$ was hung just across the centerline of the tank as the cathode, which was connected to a pulse generator (Bubble Generator, MN-305, Sugawara, Japan). The anode was allocated near the top of the tank, which thereby would not interfere with the floc motion. The pulse generator produced electrical pulses with intervals of $5 \mathrm{~ms}$; chains of tiny hydrogen bubbles were yielded and rose from the cathode. The images, scanned from a window of size $3 \times 2.3 \mathrm{~mm}$ or $5 \times 3.7 \mathrm{~mm}$, were recorded and sent continuously to a workstation. The cross-sectional area of the floc and the Feret diameter along the horizontal axis $\left(F_{x}\right)$ and along the vertical axis $\left(F_{y}\right)$ were recorded. The center of the floc was allocated at the midpoint of the two Feret diameters. The centers and sizes of the rising bubbles were determined using their cross-sectional area and the center of mass data. Tracing the centers of all rising bubbles, the individual bubble velocity $\left(V_{b}\right)$ could be obtained as a function of time. The extent of advective flow through the sludge floc could be estimated accordingly [18].

\subsection{Confocal laser scanning microscope}

The present work employed a CLSM (OLYMPUS BX50) equipped with an image processor (OLYMPUS FV5 PSU) and an argon laser source to stimulate the fluorescence. The sludge floc was imaged with a $10 \times$ objective with the software FLUOVIEW version 3.0. The microscope scanned the samples at fixed depth and digitized the images obtained.

Sludge flocs for CLSM analysis were first fixed with $3 \%$ paraformaldehyde in phosphate-buffered saline (PBS). Then the fixed sample was embedded in low-melting-point agar (with melting point of $75^{\circ} \mathrm{C}$ and gelling point of $38^{\circ} \mathrm{C}$ ) for the fluorescent in situ hybridization (FISH). In this study, we used the probes EUB338 (labeled by rhodamine) and ARCH915 (labeled by tetrachlorofluorescein) for detection of members of the domain Bacteria with a high cellular ribosome content and those that cannot be detected by EUB338 [23]. The stained samples were washed three times to remove extra probes by hybridization buffer solution.

\section{Results and discussion}

\subsection{Free-settling test}

Figure 4 illustrates microphotographs of a floc moving in the settling tube. Its terminal velocity $(V)$ was measured as $5.43 \mathrm{~mm} / \mathrm{s}$. The floc is apparently not perfectly spherical. To incorporate the shape effect we adopted the concept of equivalent diameter, which is defined as the equivalent diameter of a circle that exhibits the same area as the projection area of the floc. The result is $1820 \mu \mathrm{m}$. The corresponding Reynolds number is thereby estimated as 9.9, beyond the creeping-flow regime. Table 1 lists the settling velocity data.

Based on the commonly adopted Eq. (1) with $\Omega=1$ and $C_{D}=34 / R e$, the floc densities and porosities could be estimated and are also listed in Table 1. As demonstrated in the 


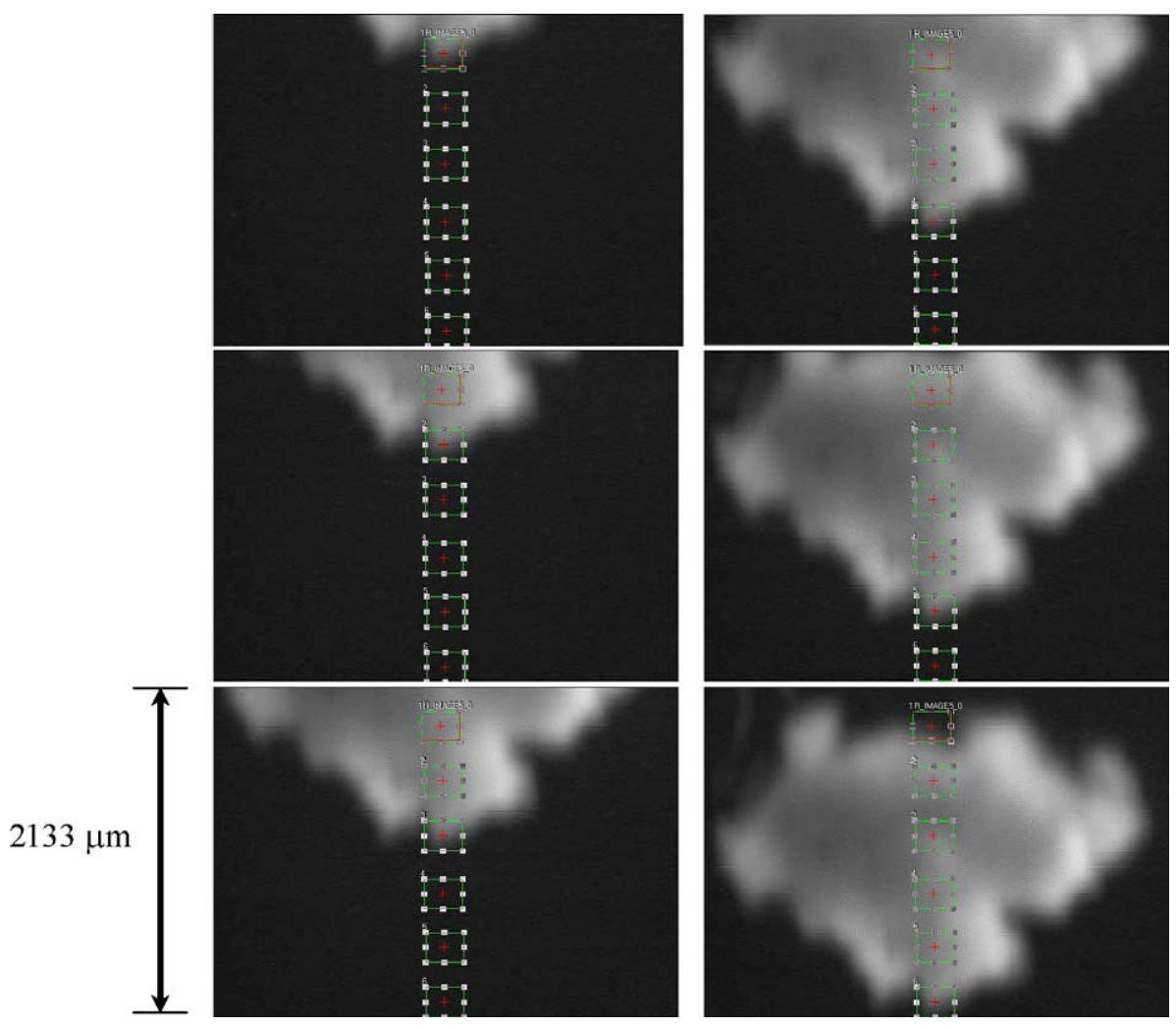

Fig. 4. Free settling of a floc flocculated at $160-\mathrm{ppm}$ polyelectrolyte. Frame interval $=0.07 \mathrm{~s} . d_{f}=1820 \mu \mathrm{m} ; V=5.43 \mathrm{~mm} / \mathrm{s} ; R e=9.9$.

Table 1

Estimated floc densities and porosities based on free-settling test

\begin{tabular}{ccccc}
\hline (a) & $\begin{array}{c}d_{f} \\
(\mu \mathrm{m})\end{array}$ & $\begin{array}{c}V \\
(\mathrm{~mm} / \mathrm{s})\end{array}$ & $\begin{array}{c}\left(\rho_{f}-\rho\right)^{\mathrm{a}} \\
\left(\mathrm{kg} / \mathrm{m}^{3}\right)\end{array}$ & $\begin{array}{c}\text { Porosity } \\
(-)\end{array}$ \\
\hline 1 & 1850 & 5.43 & 4.1 & 0.99 \\
2 & 1740 & 4.88 & 4.2 & 0.99 \\
3 & 1820 & 5.81 & 4.6 & 0.99 \\
4 & 2020 & 6.05 & 3.9 & 0.99 \\
5 & 1980 & 5.90 & 3.9 & 0.99 \\
6 & 1660 & 4.49 & 4.2 & 0.99 \\
7 & 1710 & 5.28 & 4.7 & 0.99 \\
8 & 2220 & 6.80 & 3.6 & 0.99 \\
9 & 1800 & 5.29 & 4.2 & 0.99 \\
\hline
\end{tabular}

a Buoyant density estimated using Eq. (1) with $\Omega=1$ and $C_{D}=34 / R e$.

b Porosity estimated using Eq. (2) with $\rho_{m}=1450 \mathrm{~kg} / \mathrm{m}^{3}$.

pertinent literature, the floc density is close to that of water and its porosity is extremely high: $0.98-0.99$.

\subsection{Buoyant floc porosity}

Table 2 lists the measured stick deformation for five flocculated, unfrozen flocs. Over the floc size range 1820$2010 \mathrm{~mm}$, the stick deformation was $0.058-0.206 \mathrm{~mm}$, giving a buoyant weight of $10-37 \mu \mathrm{g}$. These tiny flocs allowed no direct measurement with a commercial electronic balance.

Based on the buoyant weight listed and the densities of solids and water we can calculate the porosity based on mass
Table 2

Estimated floc densities and porosities based on stick deformation measurement (160-ppm flocculated sludge flocs)

\begin{tabular}{ccccc}
\hline $\begin{array}{c}d_{f} \\
(\mu \mathrm{m})\end{array}$ & $\begin{array}{c}Y \\
(\mathrm{~mm})\end{array}$ & $\begin{array}{c}\text { Buoyant weight } \\
(\mu \mathrm{g})\end{array}$ & $\begin{array}{c}\left(\rho_{f}-\rho\right)^{\mathrm{a}} \\
\left(\mathrm{kg} / \mathrm{m}^{3}\right)\end{array}$ & $\begin{array}{c}\text { Porosity }^{\mathrm{b}} \\
(-)\end{array}$ \\
\hline 1820 & 0.206 & 37.4 & 12 & 0.97 \\
1930 & 0.160 & 29.1 & 7.7 & 0.98 \\
2010 & 0.074 & 13.5 & 3.2 & 0.99 \\
1740 & 0.058 & 10.6 & 3.8 & 0.99 \\
2010 & 0.124 & 22.6 & 5.3 & 0.98 \\
\hline
\end{tabular}

${ }^{\text {a }}$ Buoyant density of floc is calculated using formula $\left(\rho_{f}-\rho\right)=E Y /$ $\left[(\pi / 6) d_{f}^{3} g\right]$.

b Porosity estimated using Eq. (2) with $\rho_{m}=1450 \mathrm{~kg} / \mathrm{m}^{3}$.

balance calculation. Table 2 also lists these results. A closeto-unity porosity was also noted. This occurrence correlates with the rough estimate based on the free-settling test (Table 1). An almost nonexistent floc is suggested.

\subsection{Extent of advective flow}

Figure 5 demonstrates a sequence of microphotographs for an original floc (diameter $1740 \mu \mathrm{m}$ ) while interacting with the rising bubbles. The bubble indicated by the arrow locates just beneath the floc. It is noticeable that the indicated bubble could not penetrate into but was "pushed" downward by the floc. Tracing the movement of other bubbles, $15-24 \%$ approaching flow would penetrate the floc (the advective flow). This result correlates with the experimental 


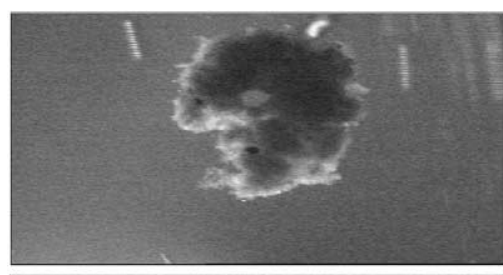

(a)
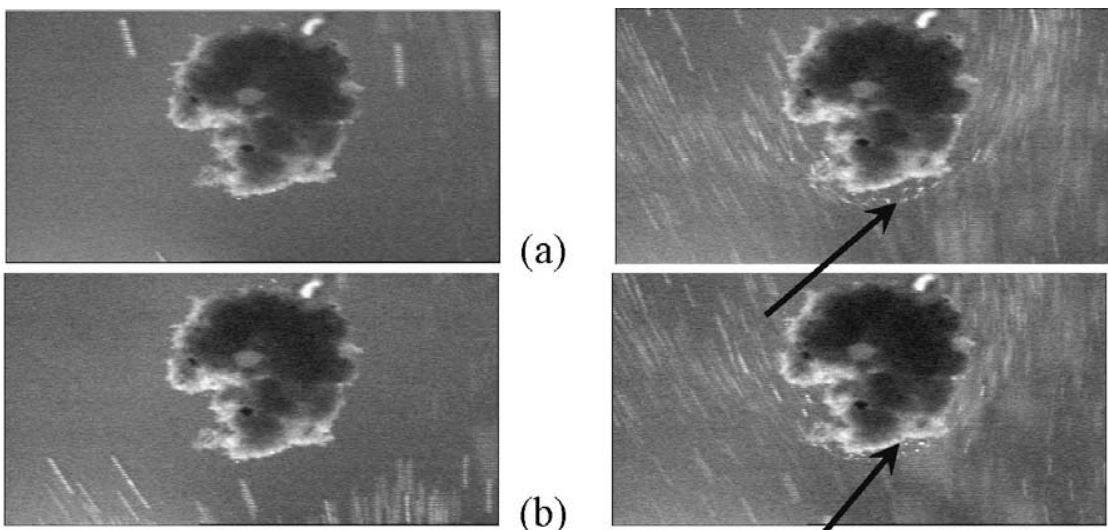

\section{(b)}

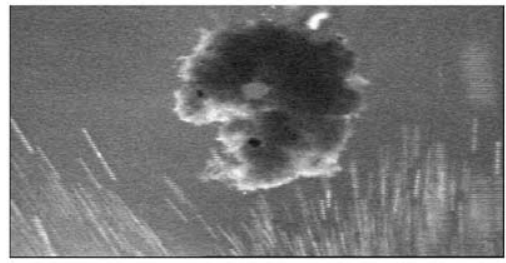

(c)

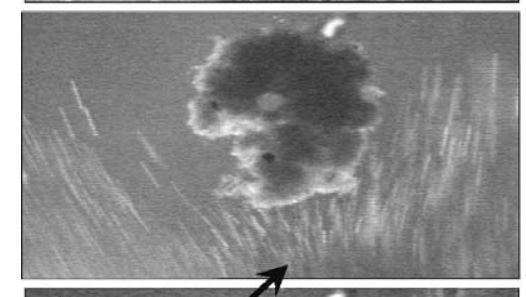

\section{(d)}
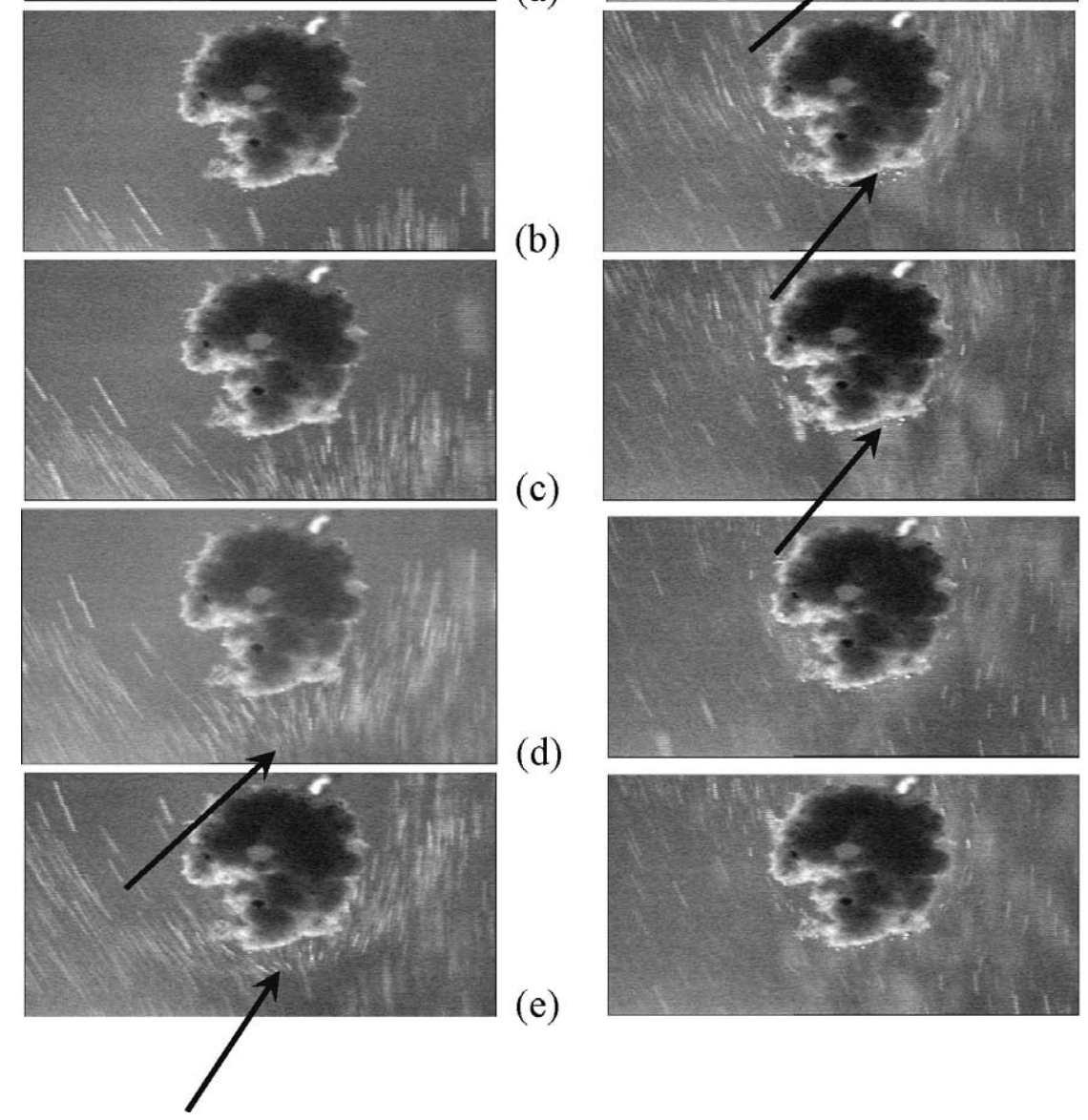

(f)
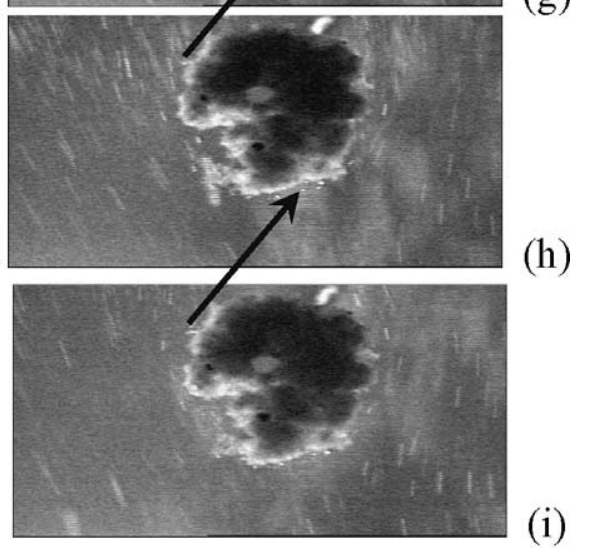

(h)

(1)

(e)

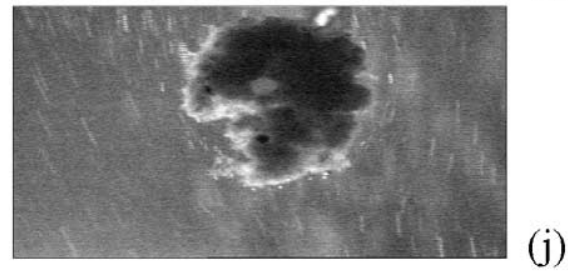

Fig. 5. Bubble-tracking of the fluid flow field around a 160-ppm flocculated floc. Frame interval $=0.03 \mathrm{~s}$. Arrows indicate the position of a specific bubble approaching the floc.

finding by Tsou et al. [18,19] but are not correspond to the extremely void floc interior indicated by the free-settling and stick deformation tests.

\subsection{CLSM imaging}

Figure 6 demonstrate the sequential CLSM sections at $1.5-\mu \mathrm{m}$ intervals for the sludge flocs conditioned at $160 \mathrm{ppm}$ of polyelectrolyte. The floc interior is highly heterogeneous. Clusters of densely packed particles were observed in the floc. With these CLSM images the three-dimensional images for the flocs were reconstructed and demonstrated in Fig. 7. The floc interior is highly heterogeneous. Clusters of densely packed particles could be observed. The filamentous bacteria that form the "backbone" of the floc architecture are easily identified.

The software Inspector (Matrox) analyzed the image. The pixels in the images were first converted into a gray scale, from which the histogram for pixels versus luminescence intensity was constructed. A threshold intensity was chosen to divide the whole image into black (solid phase) and white (void space). The area fraction of white parts was taken as the "two-dimensional porosity" [24]. We took the point exhibiting the highest slope on the curve of porosity versus luminescence intensity as the boundary separating the solid and void phases. The obtained porosity commonly exhibits a maximum relative error of less than $2 \%$. The twodimensional porosities for the original floc flocculated at $160 \mathrm{ppm}$ polyelectrolyte were $0.66 \pm 0.07$. Most significantly, the floc interior is not so void as listed in Tables 1 and 2 (ca. 99\%); on the contrary, the bacterial phase apparently occupied at least one third of the floc interior. This value underestimates the true solid fraction since (1) the present CLSM could not detect the solid phase other than the eubacteria and (2) as Li and Yuan [15] stated, the pores between the bacteria in the floc may be clogged by the cell's 

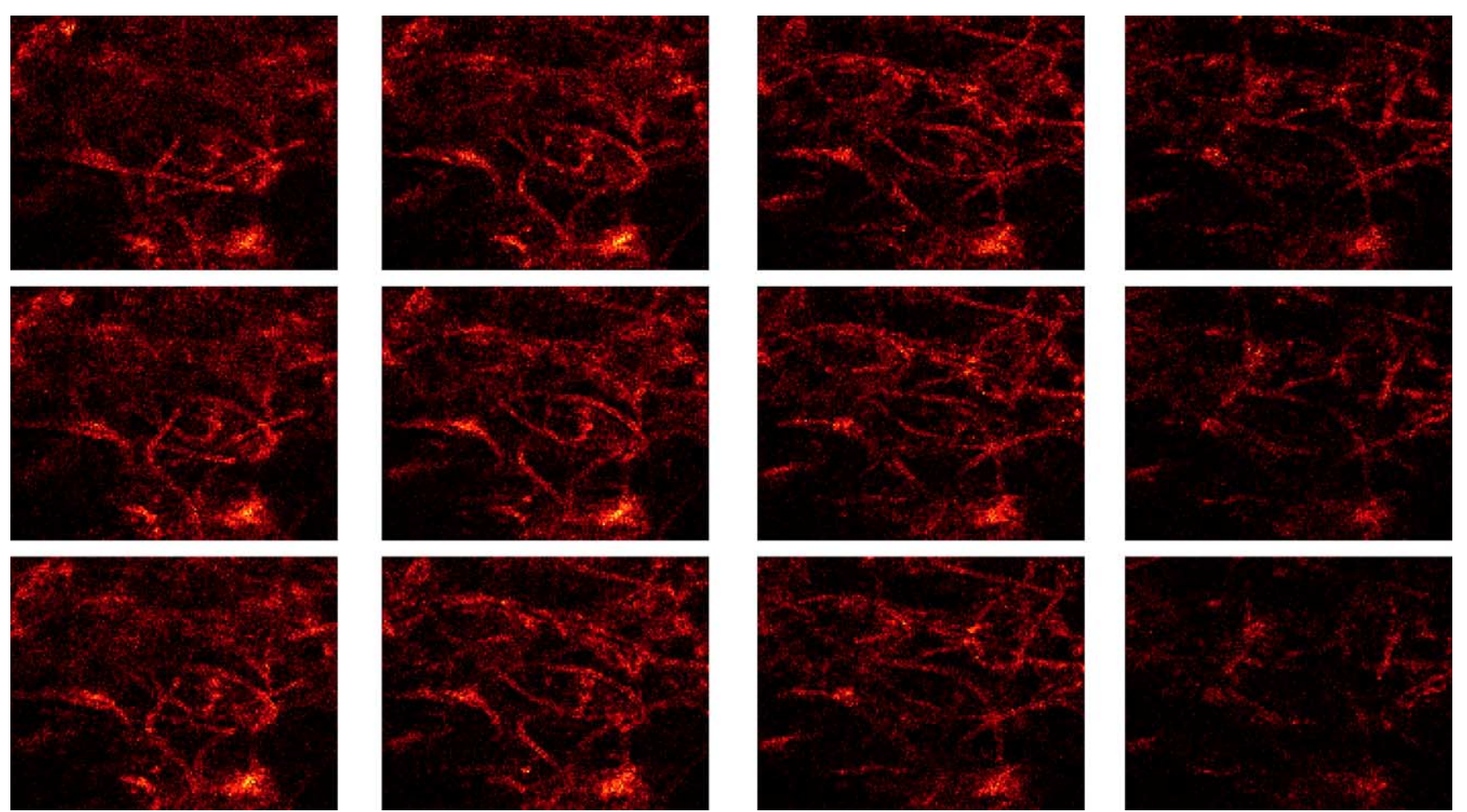

Fig. 6. Sequential sections of CLSM images of the flocculated floc (left-up to right-down) at 1.5 - $\mu$ m interval (160 ppm polyelectrolyte).

exopolymeric material, which could not be probed by the current DNA probe EUB338. Hence, the porosity of the floc interior should be less than 0.66 for the unfrozen flocs and less than 0.55 for slowly frozen/thawed flocs. This floc picture with a rather dense interior differs from the nearly void structural model reported by Tables 1 and 2, but correlates with the low extent of advective flow noted in the bubbletracking test. A clear discrepancy exists between the abovementioned experimental observations on floc porosity.

\subsection{Porosity and interior structure}

Figure 8 demonstrates a schematic of a floc (of diameter $d_{f}$ ) interior for interpreting the observed discrepancy in porosity measurement, recognizing that a vast amount of water is in fact associated with the solid phase and not really flowable in the floc. Within the floc there are bacteria and other microorganisms distributed in a fractal-like manner, which yield pores of all sizes. The solid phase, demonstrated as the shaded regime in Fig. 8 with a density of $1450 \mathrm{~kg} / \mathrm{m}^{3}$, is mainly contributed by the cell wall and other inert material, which only occupy 1-2\% of the whole space by volume (Table 2, termed as $\varepsilon_{b}$ ). In real floc the whole cells (the solid wall and the intracellular water in Fig. 8), together with all the adsorbed excellular polymer and bound water, should be regarded as a solid phase $[25,26]$. Restated, since the advective water flow cannot pass through the apparently void fraction of the floc in buoyant weight measurement, the porosity corresponding to the hydrodynamic drag force is much lower than $\varepsilon_{b}$ (termed as $\varepsilon_{t}$ ). This finding corresponds to the observations in the bubble-tracking test and the CLSM imaging.

Hence the force balance for the floc could be stated as follows:

$$
\begin{aligned}
& \frac{\pi}{6} d_{f}^{3}\left(1-\varepsilon_{b}\right)\left(\rho_{m}-\rho\right) g \\
& \quad=F_{S}=\left(\frac{\pi}{4} d_{f}^{2}\right)\left(\frac{1}{2} \rho V^{2}\right) C_{D} \Omega\left(\varepsilon_{t}(\vec{r})\right) .
\end{aligned}
$$

The $\varepsilon_{b}$ at the right of Eq. (4) is the buoyant porosity, and at the right, the correction factor $\Omega$ depends on the distribution of the porosity $\varepsilon_{t}$ (function of $\vec{r}$ ). In Tambo and Watanabe [20], $\varepsilon_{t}$ is taken as zero (no advective flow and $\Omega=1$ ); then by equating Eq. (4) a close-to-unity $\varepsilon_{b}$ is resulted, as listed in Table 1. A rather high $\varepsilon_{b}$ would result if the permeability models listed in [1] were employed to estimate $\Omega(<1)$ and $\varepsilon_{b}=\varepsilon_{t}$. The correspondence of the $\varepsilon_{b}$ s estimated by the free-settling test (assuming $\Omega=1$ or $\Omega<1$ ) and the buoyant weight measurement does not justify the accuracy of the former. Instead, as $\mathrm{Wu}$ et al. [27] remarked, the permeability for a heterogeneous floc could be much higher than that predicted by the homogeneous model at the same overall porosity since the large pore in floc allow easy advective flow. Only a nearly void floc interior would achieve this level of permeability when the solids phase distributed uniformly in the floc interior.

Recent works directly measured the floc permeability [26, 28-31] and employed it to estimate the drag force exerted on a moving floc $[32,33]$. These works assumed a uniform permeability over the floc (and hence, a constant $\varepsilon_{t}$ ) but did not 

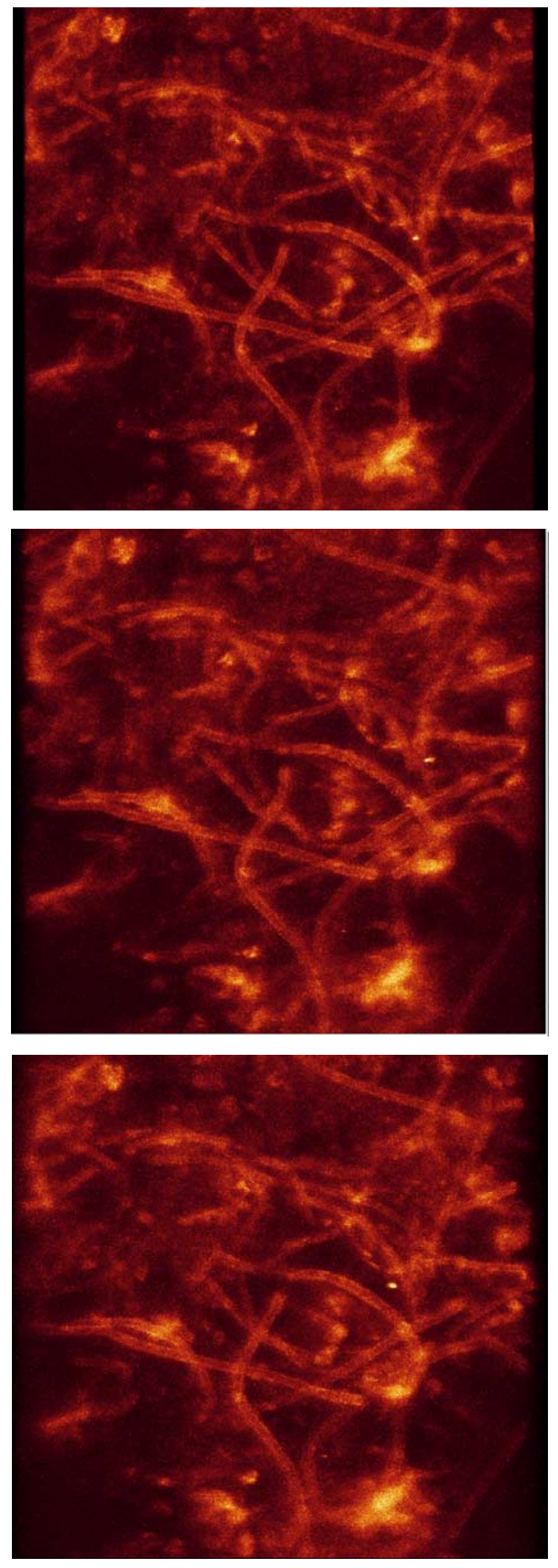

Fig. 7. Three-dimensional reconstruction of the floc interior viewed at different angles (160-ppm polyelectrolyte dose).

correspond to data listed in Table 1 or in Fig. 6. These authors assumed that the permeability is attributable to the flow resistance through large pores only, and these large pores are distributed somewhat uniformly within the floc.

For an unfrozen floc, $\varepsilon_{b}$ is close to unity (buoyant weight measurement) and $\varepsilon_{t}$ is less than 0.64 (Figs. 6 and 7), or probably less than 0.5 if the solid phase not detectable by CLSM is taken into account. The former controls the buoyant weight of the sludge floc, while part of the latter (merely the large but fine pores in the floc) contributes to the hydrodynamic drag force experienced by a moving floc. Moreover,

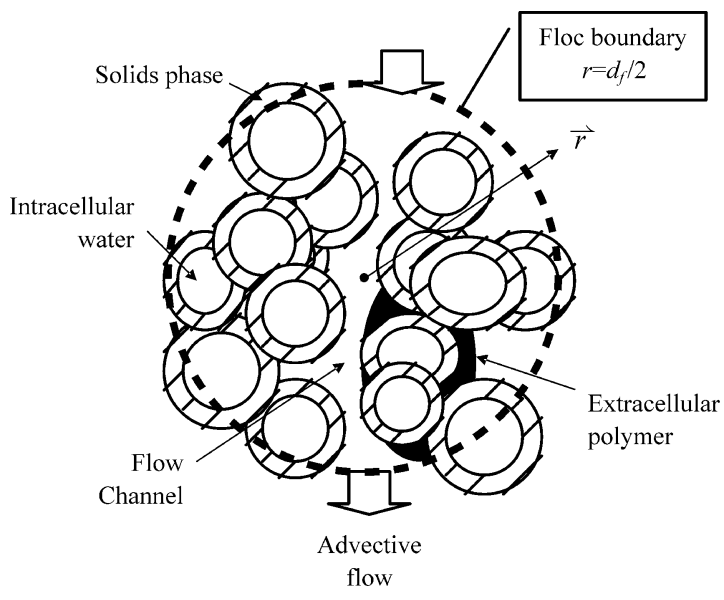

Fig. 8. Schematics of floc model proposed for interpreting the distinct floc porosities observed using different measurement methods.

the distribution rather than the mean value of $\varepsilon_{t}$ controls the extent of advective flow, whence the corresponding hydrodynamic drag force. No simple correlation exists between $\varepsilon_{b}$ and $\varepsilon_{t}$.

\section{Conclusions}

This work estimated the porosities of polyelectrolyteflocculated activated sludge flocs based on free-settling tests, buoyant weight measurements, and confocal laser scanning microscopy (CLSM) tests. The extent of advective flow was estimated based on the bubble-tracking test. For the freesettling test, the settling velocities of the flocculated floc were measured. The estimated floc density assuming an impermeable interior, which was known to be incorrect, was ca. 0.99. The buoyant weight of flocs was reported for the first time ranging from 10.6 to $37.4 \mu \mathrm{g}$ for floc sizes of 1740 $2010 \mu \mathrm{m}$, giving a buoyant density of $0.97-0.99$. On the other hand, the extent of advective flow through flocs was estimated to be only 15-24\%. The CLSM images suggested that the floc porosity was less than $64 \%$. A discrepancy exists between the porosities estimated by various tests.

A floc model was proposed based on the understanding that a vast amount of bound water in the floc was regarded as void in buoyant weight measurement, but was impermeable for advective flow. The true solid phase (density of $1450 \mathrm{~kg} / \mathrm{m}^{3}$ ) could occupy merely $1-2 \%$ of the floc interior, giving a picture of an extremely void interior. However, in real flocs the whole cells, together with all the adsorbed excellular polymer and bound water, should be regarded as the solid phase. Hence the porosity estimated based on CLSM and bubble-tracking tests was much lower than the buoyant weight measurement. We proposed that the extent of the advective flow depends on the distribution rather than the mean value of the porosity. No simple correlation exists between porosities measured by different tests. 


\section{References}

[1] D.J. Lee, G.W. Chen, Y.C. Liao, C.C. Hsieh, Water Res. 30 (1996) 541.

[2] D.H. Li, J. Ganczarczyk, Water Res. 21 (1987) 257.

[3] D.H. Li, J. Ganczarczyk, Environ. Sci. Technol. 23 (1989) 1385.

[4] D.H. Li, J. Ganczarczyk, Biotechnol. Bioeng. 35 (1990) 57.

[5] D.J. Lee, J. Chin. Inst. Chem. Eng. 25 (1994) 201.

[6] D.J. Lee, Water Res. 33 (1999) 1116.

[7] R.M. Wu, D.J. Lee, T.D. Waite, J. Guan, J. Colloid Interface Sci. 250 (2002) 383.

[8] D.N. Thomas, S.J. Judd, N. Fawcett, Water Res. 33 (1999) 1579.

[9] X. Li, Y. Yuan, Water Res. 36 (2002) 3110.

[10] P. Tang, J.A. Raper, Powder Technol. 123 (2002) 114.

[11] G.C. Bushell, Y.D. Yan, D. Woodfield, J.A. Raper, R. Amal, Adv. Colloid Interface Sci. 95 (2002) 1.

[12] A.S. Kim, K.D. Stolzenbach, J. Colloid Interface Sci. 253 (2002) 315.

[13] X. Li, B.E. Logan, Environ. Sci. Technol. 31 (1997) 1229.

[14] X. Li, B.E. Logan, Environ. Sci. Technol. 31 (1997) 1237.

[15] X. Li, Y. Yuan, Environ. Sci. Technol. 36 (2002) 387.

[16] S. Chellam, M.R. Wiesner, Water Res. 27 (1993) 1943.

[17] S. Veerapanchi, M.R. Wiesner, J. Colloid Interface Sci. 177 (1996) 45.
[18] G.W. Tsou, R.M. Wu, P.S. Yen, D.J. Lee, X.F. Peng, J. Colloid Interface Sci. 250 (2002) 400.

[19] G.W. Tsou, R.M. Wu, P.S. Yen, D.J. Lee, X.F. Peng, J. Chem. Eng. Jpn. 35 (2002) 540.

[20] N. Tambo, Y. Watanabe, Water Res. 13 (1979) 409.

[21] F. Zartarian, C. Mustin, G. Villemin, T. AitEttager, A. Thill, J.Y. Bottero, J.L. Mallet, D. Snidaro, Langmuir 13 (1997) 35.

[22] P.A. Wilderer, H.J. Bungartz, H. Lemmer, M. Wagner, J. Keller, S. Wuertz, Water Res. 36 (2002) 370.

[23] R. Witzig, W. Manz, S. Rosenberger, U. Kruger, M. Kraume, U. Szewzyk, Water Res. 36 (2002) 394.

[24] C.P. Chu, M.R. Chang, D.J. Lee, Sep. Sci. Technol. 38 (2003) 967.

[25] D.J. Lee, Y.H. Hsu, Water Environ. Res. 67 (1995) 310.

[26] C.C. Wu, C. Huang, D.J. Lee, Water Res. 32 (1998) 900.

[27] R.M. Wu, D.J. Lee, P.J. He, J. Chin. Inst. Chem. Eng. 34 (2003) 275.

[28] R.M. Wu, W.H. Feng, I.H. Tsai, D.J. Lee, Water Environ. Res. 70 (1998) 1258.

[29] R.M. Wu, G.W. Tsou, D.J. Lee, Chem. Eng. J. 80 (2000) 37.

[30] R.M. Wu, G.W. Tsou, D.J. Lee, Adv. Environ. Res. 4 (2000) 163.

[31] R.M. Wu, G.W. Tsou, D.J. Lee, J. Chin. Inst. Environ. Eng. 11 (2001) 265.

[32] R.M. Wu, D.J. Lee, Water Res. 32 (1998) 860.

[33] R.M. Wu, D.J. Lee, Chem. Eng. Sci. 53 (1998) 3571. 